\title{
ЛИНГВИСТИЧЕСКИЕ ОСОБЕННОСТИ ПРОИЗВЕДЕНИЯ МЕМУАРНОГО ЖАНРА «MÉMOIRES ET DICTÉES» («ВOCПОМИНАНИЯ И ЗАПИСКИ») Ж. СИМЕНОНА
}

В данной статье рассматривается проблема определения и анализа идиостилевых черт мемуаров Жоржа Сименона «Mémoires et dictées ( Воспоминания и записки») с позиции современной лингвистики текста и комплексной лингвостилистической интерпретации характера мемуаров на материале французского языка.

Мемуарная литература - литература в жанре мемуаров, разновидность документальной прозы и в то же время один из видов «исповедальной прозы». Актуальность, предпринятого исследования обусловлена, в первую очередь, массовым распространением мемуарного жанра в литературе. Во-вторых, она определяется значительным интересом в современной лингвистике и относится к «пограничным» жанрам (среди них эссе биографии, мемуары, дневники и т.д.), что объясняется процессами трансформации жанровой системы на рубеже XIX-XX вв. в условиях очередного кризиса европейского художественного сознания. В этой связи особое значение для лингвистики приобретает анализ идиостиля автора мемуаров и, соответственно, совокупности языковых средств как уникального авторского способа реализации индивидуальной языковой картины.

Проблема и вопросы жанрового определения мемуаров рассматривались в трудах многих ученых и практи ков, но, в основном, литературоведческого характера на материале Лежена Ф. и Шрайбера Э. Л. Из отечественных работ этого направления можно выделить Гальперина И. Р., Виноградова В. В., Нюбину Л. М. Вместе с тем вопросы лингвостилистического анализа мемуаров на материале французского языка еще не получили достаточного освещения.

Жорж Сименон - французский писатель бельгийского происхождения, один из самых известных представителей детективного жанра, с именем которого связано особое направление внутри детективного жанра литературы - социально-психологический роман. Сименон писал не только «чистые» детективы, но также и произведения, посвященные драматическому уделу личности в обществе. После 1972-го г. Жорж Сименон решил оставить детективные романы позади, и стал издавать только мемуары.

Анализ мемуарного произведения Ж. Сименона «Mémoires et dictees») («Воспоминания и записки») помог выявить его индивидуально-авторские особенности, которые характеризуются использованием минимума выразительных средств для передачи незаметных движений человеческой души, очерчивая при этом характер человека.

В работе автором доказано, что произведение Ж. Сименона «Воспоминания и записки» в полной мере соответствует критериям мемуарного жанра: произведение характеризуется субъективностью, присутствует ретроспективная композиция, сюжетность и четкая прорисовка создают эффект достоверности. Лексико-грамматические и стилистические особенности текста определяют идиостиль Ж. Сименона. Среди них автор статьи выделяет: использование числительных и дат, фразеологизмов при описании характера человека и манере его общения, а также при описании локальных характеристик; наличие простых и сложных предложений, глаголов настоящего и прошедшего времени использование метафоры, эпитетов и сравнения. Все переводы выполнены автором данной статьи.

Ключевые слова: идиостиль, мемуары, лекси ко-грамматические особенности, стилистические особенности текста, субъективность, ретроспективная композиция, сюжетность.

N. Dyumon

\section{LINGUISTIC FEATURES OF THE MEMOIR GENRE WORK "MÉMOIRES ET DICTÉES" ("MEMOIRS AND NOTES") BY G. SIMENON}

The article focuses on the problem of identification and analysis of specific features of the idiostyle of Georges Simenon's memoirs "Mémoires et dictées ("Memoirs and Notes") from the viewpoint of modern linguistics of the text and complex stylistic interpretation of the character of memoirs on the material of the French language

The relevance of the research is determined by the following facts: 1) great popularity of the memoir genre in literature; 2) keen interest of the modern linguistics to "borderline" genres (essays, biographies, memoirs, diaries, etc). In this regard, the analysis of the author's idiostyle and different linguistic means is very important as it lets us understand unique author's way to express his point of view.
Georges Simenon is a French writer from Belgium, one of the most famous representatives of the detective genre whose name is associated with a special trend in the detective literature - social-psychological novel. G. Simenon wrote not only "pure" detective stories, his works are also dedicated to the dramatic destiny of an individual in modern society. In $1972 \mathrm{G}$. Simenon decided to stop writing detective novels and began to publish only memoirs.

The analysis of the memoirs by $\mathrm{G}$. Simenon "Mémoires et dictees" ("Memoirs and Notes") helped to determine his author's features, which are characterized by the use of a small number of expressive means to demonstrate imper- 
ceptible movements of the human soul, while outlining the character of a person.

It is proved in the article that lexical, grammatical and stylistic features of the text "Mémoires et dictées" ("Memoirs and Notes") determine G. Simenon's idiostyle. They are: use of numerals and dates, use of the phraseological units to describe a person's character, his manner of speaking

Как литературный жанр мемуарная проза зарождается в XIX-XX вв. во Франции, на почве зарождающегося индивидуалистического самоощущения. По своей сути, мемуары - записки - событиях, в которых автор принимал участие или которые известны ему от очевидцев-современников, или людей, с которыми был знаком. В отличие от автобиографии, автор сосредоточен на окружающем мире, а не на истории своей личности. Мемуарные произведения примечательны тем, что они создаются людьми, для которых практика письма не является обязательной в жизни $[3$, с. 3].

Мемуарные тексты представляют собой фриксированную организацию высказываний. Вся представленная информация включает в себя информацию о годе, месте рождения и событиях личной жизни. Текстам мемуаров характерны повествования о жизненных событиях, которые несут в себе исторический характер. Мемуары являются одним из видов документально-художественного стиля. Мемуарам присущи черты документальной прозы [4, с. 2].

Для мемуарной прозы характерна ретроспективность - возвращение к прошлому. Ретроспективность в произведении характеризуется с помощью изобразительно-выразительных средств. Она предназначена для сообщения о прошлой жизни автора. Текст мемуарного произведения строится на основе строгой хронологии. Происходит взаимодействие двух временных планов: прошлого и настоящего [2, с. 211, 344-350].

Мемуары состоят из заглавного текста, предисловия, вступления, а также, возможно, фотографий с места событий. Они представляют из себя художественный текст, который состоит из нескольких глав. В свою очередь, каждая глава имеет свое имя и разную внутреннюю структуру. Не имея названия, глава нумеруется в соответствующем порядке. Внутри главы можно увидеть текст, который поделен на абзацы в соответствии со сменой событий, о которых говорит автор.

Произведение Ж. Сименона «Mémoires et dictées» («Воспоминания и записки») в полной мере соответствует критериям мемуарного жанра: произведение характеризуется субъективностью, присутствует ретроспективная композиция, сюжетность и четкая прорисовка создают эффект достоверности.

На страницах мемуарного произведения Сименона "Mèmoires et dictées" можно увидеть, как автор задает себе много вопросов, на которые тут же отвечает. Такие ответы помогают читателю понять, каким был Сименон и чем дорожил [5] and some local characteristics; use of simple and complex sentences, present and past tenses; use of metaphors, epithets and comparisons. All translations are by the authors of this article.

Key words: idiostyle, memoirs, lexical and grammatical features, stylistic features, subjectivity, retrospective composition, plot

В течение десяти лет Сименон беседовал сам с собой перед диктоффоном, пытаясь сказать о том, что он «познал в течение долгой жизни», о том, что запало ему в сердце и душу [5]

То, что он надиктовал, печаталось на машинке секретарем писателя, а потом отправлялось в парижское издательство «Presses de la Cité». Таким образом появился двадцать один том воспоминаний Сименона. Именно такая нетрадиционная форма изложения оказалась наиболее приемлемой для писателя, который стремится высказаться, открыть душу незнакомым людям и помочь им понять самих себя и окружающий мир.

Воспоминания Сименона обладают большой искренностью, особенно в том, что касается его интимной жизни [6].

В своем цикле «Mémoires et dictées» («Воспоминания и записки») Сименон мысленно возвращается к прожитым годам, ко времени его литературных дебютов в Париже или к воспоминаниям о его путешествиях:

1. "En tout cas, j'ai personnellement des souvenirs d'enfance immuablement remplis de soleil. Par exemple, les dimanches et lundis de Pâques». «Во всяком случае, у меня лично воспоминания детства неизменно залиты солнцем. Например, пасхальные воскресенья и понедельники». "Liège est une ville pluvieuse. Cependant, toutes les Påques, comme je me souviens, étaient ensoleillées et chaudes; il était possible de faire sans veste et manteau et de la force dans un nouveau chapeau de раіlle». - «Льеж - дождливый город. Однако все пасхи, какие я помню, были солнечные и теплые можно было обойтись без курточки и пальто и пофорсить в новенькой соломенной шляпе» [7].

Однако, он скрупулезно избегает того, что может походить на сенсацию, вызывать у читателя нездоровое любопытство. Сименон ведет неторопливое повествование, как бы стараясь ответить самому себе на вопросы в том, кем он был, чем была его жизнь и понять смысл своих поступков. Что указывает на субъективность произведения.

В центре внимания Сименона-писателя всегда простой человек, который полон героических порывов, надежд, повседневного мужества [5]

Писатель, обходясь минимумом изобразительных средств, в своих произведениях передал почти незаметные движения человеческой души, несколькими фразами очертил характер человека. Это - одна из сильных сторон мастерства романиста. Страницы воспоминаний прослеживают движения художественных поисков Сименона между двумя полюсами - изображением человека «вообще» и изображением людей в их конкретной социальной и исторической сущности. 
Текст мемуарного произведения «Mémoires et dictèes» характеризуется определенными лексическими особенностями, которые определяются обширным количеством числительных и дат ('le douze avril', 'mille neuf cent soixante huitième année'). Для произведения «Я диктую. Воспоминания» характерен разговорный тип письма. В своем произведении автор использует понятную, живую свободную и доступную для читателя речь. Автор свободен в выборе слов и выражений. Такой стиль часто используется в беседах со знакомыми людьми в непринужденной обстановке.

В ряду главных жанрообразующих средств выделяются лексические единицы, захватывающие жизненные этапы, поскольку жанр мемуарной прозы посвящен описанию жизни. Когда автор описывает какое-то важное событие в его жизни он использует новую дату.

2. "La même chose qu'en 1929. J'ai écrit mon premier roman. - То же самое произошло в 1929 Тогда я написал свой первый роман.» / «А 1938 j'ai découvert les autobiographies. - B 1938впервые открыл для себя автобиографрии.» / «J'ai perdu ma femme à 1930, c'est pourquoi j'al quitté Liège. - Моя женщина ушла от меня в 1930, именно поэтому я покинул ЛЬеж» / «J'espère que je passerai la frontière à 1960. - Наdeюcb, чmo я пересеку границу в 1960-м» / «22 décembre 1973. Chaque année, à la même heure, une émission de télévision montre l'une des salles de l'Elysian Palace, oủ cent hommes et femmes âgés sont assis, nettoyés, brossés, vêtus de ce qu'ils ont de mieux; peut-être même ces vêtements qu'ils ont reçus dans le vestiaire, comme des figurants au théâtre. -22 декабря 1973. Каждый год в это время по телевидению показывают один из залов Елисейского дворца, где сидят сто стариков и старух, чисто вымытых, причесанных, одетых в самое лучшее, что у них есть; возможно даже, эти наряды они получили в гардеробной, точь-вточь как статисты в meampe.» / "On nous dit non seulement ce qui se passera en 1980, mais bien plus tard - en 2000; plus loin - plus, et on nous dit déjà qu'il nous attend (en disant "nous», je veux dire pas nous-mêmes) en 2030, en 2050, etc. - HaM zoворят не только о том, что будет в 1980 году но и гораздо позже - в 2000-м; дальше - больше, и нам уже возвещают, что нас ждет (аоворя "нас», я имею в виду не себя) в 2030, в 2050 году um..$»[7]$.

На протяжении произведения Сименон нередко использует англицизмы, поскольку некоторые главы были написаны писателем, когда тот путешествовал по Англии и Америке. Таким образом он становится более понятным и близким для читателя. ввиду мировой глобализации. Например:

3. "Elle savait convoquer l'autorité nécessaire pour endosser le rôle du leader. - Она знала, чmо такое авторитет и могла показать себя лидеpom.» / "Je me lève à l'aube pour faire mon footing. Я встаю на рассвете, чтобы соверuить пешую прогулку.» / "C'est beau et très cool! - Как хорошо и классно!»/ "Elle passa un shampooing à тоі. - Она мне задала головоломку. / «Le grand méchant look. - Злой вид.» / "Je relax. - Я отдыхаю.» / "Elle est fashionable. - Она модно одевается.» [7].

Также в произведении Сименона можно проследить такие англицизмы, как: «week-end (выходной день), single (один, единственный), le look (взгляд, внешность), le jean (джинсы), les stock (запас, ассортимент), un dressing (наряд, одежда), le sandwich (сэндвич), la/le coach (коляска, карета)» и т.д.

Использование местоимений çа, on указывает на преобладание элементов разговорной речи в тексте:

4. «Je suppose que ça venait de ça. - Можно сказать, что именно это я и ощущал.» / "Chéri, ca va, ca vient. - Дорогая, что приходum, mo и ухоdum.» / "Surtout maintenant que ça devient sérieux. Именно сейчас все становится серьезным.» / "Quand on veut, on peut. - Kmo uщem, mom найdem.» / "Quand on aime, on partage ses secrets. Когда мы любим, мы делимся секретами.» En remplaçant nous le pronom on marque souvent l'orgueil [7].

Автор передает информацию о месте своего пребывания. месте жительства. а также описывает места своих передвижений или обозначает место. где происходили те или иные события с помощью единиц. отражающих локальные характеристики:

5. «Enfin, j'aime l'Angleterre. - Наконеи, я полюбил Англию.» / «Celui-ci est en Angleterre, à Morton. Это место находится в Мортоне, в Англии.» / "Oui, Paris sera ta Babylone. - Да, Париж станет моим собственным Вавилоном.» / "J'ai quitté Marseille il y a quelques semaines. - Я уехал uз Марселля несколько недель назад.» / "Strasbourg, Nice, Monaco... - Cmрасбуре, Нuца, Монако.... / «Ce pourrait être la Sardaigne, ou la Sicile. - Эmo может быть Сардиния или Сицилия.» / «ttalie. Un pays pleins de pâtes et de passion. - Италия. Страна полная макарон и страсти.» [7].

Необходимо отметить функционирование имен числительных, которые используются для обозначения года, дня рождения, возраста, какой-либо даты, периода времени, в течение которого совершались события. Числительные, используемые автором, являются не только простыми, но и сложными. Сложные числительные, как, например, для обозначения года, состоящие из одного или нескольких слов пишутся через десис:

6. "Je suis né en mille neuf cent troisieme. - Я родился в 1903.» / "J'ai écrit le premier roman en mille neuf cent vingt-neuf. - Я написал первый роман в 1929.» / "Je suis devenu membre de l'Académie royale de Belgique en mille neuf cent cinquante-deuxième. - В 1952-м стал членом Королевской академии Бельгии.» / "Aे la fin de mille neuf cent soixante-douze j'ai décidé de ne pas écrire plus de romans. - В конце 1972-го я решил больwe не пuсать романы.» / "Et enfin, à mille neuf cent soixante-dix-neuvième, j'ai commencé à écrire Mémoires intimes. - И, наконеи, в 1979-м я принялся писать 'Интимные романы'.» [7] 
Автор часто применяет в письменной речи оборот il y a, который служит для үказания на напичие одного или нескольких предметов:

"Là où il v a une arme, il v a un délit. - Beзde, где есть оружие, есть и преступность.» / «On dirait qu'il v a autre chose. - Говоряm, чmо ecmь u dpyaue вeщu.» / "Et quand il $v$ a de jolies femmes, j'essaie d'écouter tous les faits. - A когда речь заходит о прекрасных дамах, я пытаюсь выслушать всю информацию.» [7].

Предлог а̀ в некоторых случаях служит связью глагола и последующего существительного или местоимения:

«Je pense à cette photo. - Я думаю об этой фomoapaquu.» / Je pense beaucoup à Liège... - Я много думаю о Льеже.» / "Quand je pense à mes émotions, j'en reviens toujours à ma femme. - Каждый раз, когда я думаю о своих чувствах, я вспоминаю про свою леди.» / «Quand je pense à lui, son nom vient sur mes levres. - Когда я думаю о ней, ее имя срывается с моих әуб.» [17].

В данном случае форма Je pense à выражает факт наличия мысли о ком-то или о чем-то.

С точки зрения использования временных форм глагола, следует отметить, что в тексте используются глаголы в форме прошедшего и настоящего времени. Поскольку ретроспективность - одна из характерных черт мемуарного жанра, большая часть повествования ведется в форме прошедшего времени (Passé Composé, Imparfait):

«ll s'en passerait s'il disait la vérité. - Оно бы ему понадобилось, если бы он говорил мне правду.» / "Ce qu'il disait s'est avéré être un mensonge». «Bce, что он говорил, оказалось ложью.» «Ce qu'il disait était très éloigné de la vérité. - To, ymo $\mathrm{OH}$ говорил, было далеко от истины.» «Je savais ce qu'il pensait. - "Я знал, о чем он думал.» "Сe que je pensais n'a aucune importance». - «Tо, что я dyмал, уже не имеет никакого значения.» "J'ignore à quoi je pensais». - "Даже не знаю, о чем я думал." "ll était trois heures. II n'y avait personne dans les rues. La pluie tombait». - "Было mpu часа. На улицах никого не было. Шёл дождь.» "Је commencais et finissais chaque jour avec l'espoir». "Я начинал и заканчивал день с надеждой». "Le genre où il finissait en larmes. - "Безумный смех, который заканчивается слезами на әлазах.» «Је commencais une phrase, elle finissait». - "Я начинал предложение, а она заканчивала». "Quand il ne compenait pas quelque chose, il venait toujours me voir. - «Когда он что-нибудь не понимал, то всегда приходил ко мне» [7]

Время Imparfait выражает прошедшее действие, при совершении которого совершилось бы какое-либо действие в прошлом, для обозначения незаконченного действия, а также для описания действия в прошлом, происходящего в момент речи.

Время Passé composé обозначает временной отрезок происходящего действия, которое уже завершилось и подтверждает присутствие говорящего, в частности, в данных мемуарах.
"J'ai toujours pas compris pourquoi elle l'a fait. Я до сих пор не понял, почему она так сделала». I «- Paul, tu as compris ma demande. - Поль, ты понял, о чем я проuу.» / «Je suis revenu tard. - Я вернулся поздно.» / «J'ại bien compris cette règle. Я хорошо понял это правило» [7].

Настоящее время автором практически не используется, за исключением моментов, когда писатель описывает моменты своей жизни в настоящем. Очень часто писатель использует глагол «parler»:

"Nous parlons. apprenons à nous connaitre. мы говорим, узнаем друа друга.» / "Nous parlons au téléphone pendant une heure tous les soirs. - Mbl гвоорим по телефону каждый вечер.» / «Nous parlons de retourner vivre à Seattle. - Mы поговариваем о том, чтобы вернуться в Сиэттл.» [7].

На синтаксическом уровне языка можно отметить простые предложения, что делает речь более эмоциональной и динамичной: «Il ne l'a pas faite». - «Он этого не делал.» Сложные предложения представляют собой сложносочиненные предложения: "Je te vois maintenant et je suis heureuse». - "Я вижу тебя сейчас $и$ я счастлив.» / "Elle était un peu légère mais elle n'était pas méchante». - "Она была немного легкомысленна, но она не была злой.» и сложноподчиненные: "Je sais qu'il a peur». - "Я знаю, чего он бoumcr.» "C'est la place oú je suis né». - "Эmo место, әде я родился." "Paul est la personne que j'estime beaucoup». - «Поль - человек, которого я алубоко уважаю.» [7]. Они указывают на логическую и интеллектуальную сторону речи.

В своем произведении автор меняет темь одна за другой. Они варьируются от узкобытовых до профессиональных, морально-этических и философрских

"L'homme continue à cacher sa solitude sous sa cruauté. II présent ses avantages et ses inconvénients, ses possibilités et ses défauts. - 4eловек продолжает скрывать свое одиночество за жестокостью. Он знает свои достоинства и недостатки, свои возможности и пороки.»

Практически в любой части своего произведения Сименон использует местоимение (Я). Герой произведения - сам Сименон. Роман написан от первого числа единственного числа:

"Maintenant, c'est très important car le temps presse. - Для меня сейчас это очень важно, ведь часики-то тикают.» / "C'est la seule chose à laquelle j'ai pensé. - Эmо единственное дело, о котором я думал." / "Je l'espère de toute mon äme, mais je n'y crois pas. - Я всей душой надеюсь на это, но не верю.» [7].

Сименон использует фразеологизмы при описании человека. Таким образом, автор характеризует язык персонажа. Наиболее заметна роль фразеологизмов при описании манеры и типе речи вводимых персонажей. Такие манеры свойственны лишь одному персонажу в произведении:

"Paul a rouai jusqu'à la racine des cheveux. Поль покраснел до корней волос. » / «Paul est fort 
comme un boeuf. - Поль - здоров, как бык.»/«ll avait la tête à aifles. - Еао лицо отталкивало.» / «Ma femme a été lécère comme une plume. - Моя женщина была такой порхающей.» [7].

Но также автор использует фразеологизмы для описания ситуации:

«Tout est parti en cacahuète! - Всё пошло коту под хвост!» / "Elle en fait un fromage! - Она делаem из мухи слона!» / "Écoute, il faut appeler un chat un chat. - Послушай, называй вещи своими именамu.» / "Je suis heureux, aux anges... et très fier qu'elle accepte de m'épouser. - Я на седьмом небе от счастья из-за того, что она согласилась cmamь моей женой.» / "On a fait une montagne d'un rien. - Люди делают из мухи слона. » [7].

Говоря об эмоциональных средствах выразительности, можно выделить следующие: метафоры, сравнения и эпитеты, которые используются в тексте с цеелью создания более ярких, выразительных образов, явлений, а также выражения авторских оценок и эмоций.

«Elle avait les veux aros et saillants. - Ее глаза были на выкате.» / "La pluit aui dit clic clac. Дождь, который говорит клик клак.» / «Ill n'est pas dans son assiette. - $\mathrm{OH}$ находится не в своей тарелке.» / "Ça vient de mon coeur. - Эmo происходит из чистых побуждений.» / "ll a $\underline{\text { bu la }}$ cigarette. - $\mathrm{OH}$ взахлеб курил cuгарету.»/ "Nos yeux se sont rencontrés. - Hawu взаляды встреmuлись.» / "ll est avare comme un rat. - OH cкуn, как крыса.» / "Ma femme est un petit chou. - Моя дама-милочка.» / «ll est toujours prêt à briser notre glace. - Oн всеада готов выдать наши с ним секреты.» / "Martin est bien dans ses basquettes. Мартану хорошо в своей икуре (Мартан хорошо жuвem).» / "Martin toujours porte la culotte dans sa famille. - Мартин всегда командует в своей сеMьe.» [7].

В своем произведении Сименон часто употребляет слова с приставками - а-, анти-, непо-, меж-, сверх-: «stable - неуклонный, ferme несаибаемый, de manière professionnelle - как профессионал, d'une manière nouvelle - по-новомy, la puissance - сверхсила, apolitique - аполимичный» [7].

«Paule est restée calme et stable. - Поль ocmaвался спокойным и непреклонным.» / "Notre lien avec elle est ferme. - Наши отношения с ней несаибаемы." / "Je fais juste cela de manière professionnelle. - Я этим занимаюсь по рабоme.» / "J'imagine que j'essaye juste de regarder les choses d'une manière nouvelle. - Я просто cmaраюсь взелянуть на вещи по-новому.» / "Si elle pouvait sentirla puissance qui me traverse... - Eслu бы она могла прочувствовать силу, которая разрастаетсся вокруг меня...» [7].

В работе Сименона можно часто встретить парцелляцию. Здесь может показаться, что писатель намеренно использовал ее для привлечения внимания к отдельным частям сказанного:

"Même avec les magasins. Sur le boulevard de la Madeleine - grand, chic. Plus près du boulevard Saint-Martin - plus facile, plus accessible. - To же самое и с магазинами. На бульваре Мадлен больиие, шикарные. Ближе к бульвару Сен-Мартен - проще, доступней. / "Je leur dis. Je m'étais marié. Je retournerai pas à Liège. Je leur ai écrit des notes pour les inspirer pendant la journée. -Я сказал им, что женился. И в Льеж я не вернусь. Я написал им вдохновляющие утренние записки.» / "J'ai écrit. Un poème. Sur ma femme. J'ai écrit ça il y a 3 ans et c'est enfin d'actualité. - Я написал. Поэму. Своей женщине. Я написал ее три года назад и сейчас, наконеи, могу ее озвучить. ” I «Et j'étais prêt à fuir. Immediatement. - Я гоmos был уйти. Сразу же.» [7]

В своей работе Сименон употребляет иронию и самоиронию, чтобы читатель смог стать на место Сименона и провести параллель между воспоминаниями автора и своей жизнью. Такие слова и словосочетания писатель ставит в кавычки:

"Je sais pas. Je dois dire que j'en suis 'hereux' et 'fjer' - «Я не знаю этого». «Но должен признаться, что я 'счастлив' $и$ 'горд' насчет этого.» «Je sais ce qu'elle veut dire. Je ne 'rentrerai' pas dans les détails ic»i. - "Я знаю, что она имеет в виду. Не хочу 'входить' в детали.» "Si seulement il pouvait être aussi 'heureux' que moi». - «Желаю ему жить на покое так же 'счастливо', как 'живу' я.» [7].

Известно, что существует разница между лексическим и стилистическим значением слова, где лексика несет понятие о рефреренте, а стилистическая сторона слова несет информацию о субъекте речи и вообще о пространстве коммуникации.

Следует отметить и арго, слова и словосочетания, которые помогают определить того или иного героя к определенной социальной среде.

"Il aurait pu me tuer, en plaisantant. Son poing m'a fait l'effet d'un roc». - «Oн бы мое, uутя, убить меня. Его кулак все равно, что молоток.» (В данном примере глагол «убить» свойственно терминологии полицейских) [7].

Сименон также употребляет метафору и сравнение, которые используются для создания одних и тех же образов, и различие между ними часто является формальным и заключается в присутствии союза «как, как будто»:

"J'ai eu l'impression de jouer pour des statues. У меня было ощущение, что я говорю с истуканами.» (В данном примере речь идет о фоормальном сходстве героя со статуей (истукан), потому что стоял он, не двигаясь с места, дожидаясь свою возлюбленную.) / «Ma femme a réchauffé mon cœur comme le soleil. Sa sourire est un soleil. Моя женщина согревает меня своим теплом, словно солнце. Ее улыбка солнцу подобна.» / "Pour moi, ce fut une fatalité, inévitable comme la fin du jour, mystérieuse comme le lever du clair de lune. Для меня это было подобие злого рока, неуловимый, словно начало дня, - и таинственный, словно полнолуние.» / "Elle est comme la nuit, la tempête, et le coeur du soleil. - Она для меня словно ночь, словно буря в сердие солнца.» / "Comme si cette nuit-là mavait enlevé des choses que tu avais emportées. - Та ночь словно забрала у меня все силы, что ты мне подарила.» / "Nous avons 
parlées toute la nuit que c'était le dernier jour sur terre. - Мы проболтали всю ночь, как будто это был последний день на Земле.» / «Notre rencontre était juste comme un rêve d'une nuit d'été. - Hawa встреча была похожа на сон в летнюю ночь.». Это дает читателю возможность анализа своих ощущений и представлений с эмоциональной точки зрения [7].

Итак, используемые стилистические средства помогают автору сделать свою речь понятной и доступной читателю. Писатель передает незначительные нюансы, но в то же время дает полное представление о происходящих событиях и окружении

Анализ мемуарного произведения Ж. Сименона «Воспоминания и записки» помог выявить его индивидуально-авторские особенности и сделать автору статьи следующие выводы: 1) обходясь минимумом изобразительных средств, в своих произведениях Сименон передал почти незаметные движения человеческой души, несколькими фрразами, очертил характер человека, что является одной из сильных сторон мастерства романиста; 2) использование единиц, отражающих локальные характеристики, личного местоимения "Я», имен числительных, ссылающихся на определенную дату и единиц лексико-семантической группы наименований родства характерно для языкового воплощения жанра мемуарной прозы. Следовательно, вышерассмотренные особенности текста мемуарной прозы на лексическом и грамматическом языковых уровнях подчеркивают оригинальный текст Жоржа Сименона.

\section{Литература}

1. Валгина Н. С. Теория текста. Учебное пособие. М.: ЛОГОС, 2003. 173 с.

2. Виноградов В. В. О языке художественной прозы. М.: Наука, 1980.360 c

3. Лежен Ф. В защиту автобиографии URL: http://magazines.russ.ru/inostran/2000/4/lezhen.html (Дата обращения: 21.09.2019).

4. Нюбина Л. М. Мемурный текст как многогранный когнитивный феномен. Познание: Сборник научных трудов. URL: http://www.rusnauka.com/4_SND_2013/Philologia/3_128694.doc.htm(Дата обращения: 21.09.2019).

5. Assouline P. Simenon. Paris : Gallimard, 1992. $1059 \mathrm{c}$.

6. Le nouveau petit Robert. Dictionnaire de la langue française. Paris: Le Robert, 1993.

7. Simenon J. Mémoires et dictẻes. Paris: Presses de la cité, 1984. $147 \mathrm{c}$.

\section{References}

1. Valgina N. S. Teoriia teksta (Text theory). Moscow: LOGOS publ., 2003. 173 p. (In Russian)

2. Vinogradov V. V. O iazyke khudozhestvennoi prozy (About the language of fiction). Moscow: Nauka publ., 1980. $360 \mathrm{p}$ (In Russian)

3. Lezhen F. V zashchitu avtobiografii (In defense of an autobiography) URL: http://magazines.russ.ru/inostran/2000/4/ lezhen.html (Accessed: 21.09.2019).

4. Niubina L. M. Memurnyi tekst kak mnogogrannyi kognitivnyi fenomen (Memorial text as a multifaceted cognitive phenomenon) URL: http://www.rusnauka.com/4_SND_2013/Philologia/3_128694.doc.htm (Accessed: 21.09.2019).

5. Assouline P. Simenon. Paris: Gallimard, $19 \overline{9} 2.1059 \mathrm{~s}$.

6. Le nouveau petit Robert. Dictionnaire de la langue française. Paris: Le Robert, 1993.

7. Simenon J. Mémoires et dictées. Paris: Presses de la cité, 1984. 147 s.

\section{Сведения об авторе}

Дюмон Наталья Николаевна - кандидат филологических наук, доцент кафедры романо-германского языкознания и межкультурной коммуникации гуманитарного института Северо-Кавказского федерального университета (Ставрополь) / djumon18@mail.ru

\section{Information about the author}

Dyumon Natal'ya - PhD in Philology, Associate Professor, Chair of Roman-Germanic Linguistics and Cross-cultural Communication of North-Caucasus Federal University (Stavropol) / djumon18@mail.ru 